\title{
Resistência a compressão axial em concretos aditivados com PET (politereftalado de etileno) em substituição aos agregados
}

\author{
A. F. R. Cruz ${ }^{1 *}$, C. R. Alves², D. B. Silva ${ }^{3}$, L. N. Benedito \\ *Autor de Contato: ana.cruz@engenharia.ufjf.br \\ ${ }^{1}$ Faculdades Unificadas de Cataguases, Cataguases, Brasil \\ ${ }^{2}$ Faculdades Unificadas de Cataguases, Cataguases, Brasil \\ ${ }^{3}$ Faculdades Unificadas de Cataguases, Cataguases, Brasil \\ ${ }^{4}$ Faculdades Unificadas de Cataguases, Cataguases, Brasil
}

\begin{abstract}
RESUMO
Estudar materiais cimentícios sustentáveis é tarefa primordial, especialmente na indústria da construção civil. Este presente trabalho tem por objetivo avaliar o uso de agregados reciclados de PET em substituição aos agregados convencionais em concretos de classe C30. Assim, foram desenvolvidas diferentes dosagens: CA (dosagem de referência), CAPET 5, CAPET 10, CAPET 20 e CAPET50 (substituições em volume de 5\%,10\%, 20\% e 50\%, respectivamente, dos agregados da dosagem de referência por agregados reciclados de PET). Foram desenvolvidos ensaios para avaliar a consistência e a resistência à compressão axial. Identificou-se que, com o aumento do teor de substituições, o material perde trabalhabilidade e resistência à compressão axial, de modo que os melhores resultados foram encontrados para as substituições de 5\%.
\end{abstract}

Palavras-chave: Trabalhabilidade; Consistência; Resistência; Agregado reciclado.

\section{INTRODUÇÃO}


O concreto tradicional é constituído basicamente por cimento, agregados e água. O cimento é um material utilizado na construção civil e seu uso pode ser justificado por ele conferir uma série de características às misturas, como resistência, durabilidade e versatilidade. A indústria do cimento é um dos setores que vem crescendo nos últimos anos, movimentando bilhões de dólares em todo o mundo (THOMÉ, 2016). O cimento Portland é o tipo de cimento mais utilizado na construção civil, exercendo nas misturas cimentícias a função de aglomerante ou aglutinante. Os agregados empregados na fabricação do concreto podem ter origem natural ou artificial, sendo divididos em agregadas miúdos e agregados graúdos.

Essas misturas cimentícias são empregadas com diversas funções - estruturais ou não. Porém, pode-se destacar que, com o passar dos anos, a busca pela melhoria de suas propriedades tornou-se impulsionadora de pesquisas na indústria da construção civil. Assim, estudos de dosagem e de desenvolvimento de novos materiais e serem incorporados nessas matrizes cimentícias, a fim de melhorar ou modificar suas propriedades, tornou-se tarefa essencial no desenvolvimento tecnológico do setor da construção civil. Nesse contexto, aditivos e adições tem sido estudados ao longo dos anos e garantiram maior desempenho e qualidade dessas misturas, fatores fundamentais para garantia de vantagem competitiva das empresas construtoras frente a suas concorrentes de mercado.

Porém, vale destacar que o desenvolvimento tecnológico que impulsionou a indústria da construção civil nos últimos, trouxe com ele graves prejuízos e impactos ambientais, como a extração de recursos naturais e a geração de resíduos. Quando se pensa em uso de matérias primas produzidas no mundo, entre $40 \%$ e $75 \%$ são consumidas na construção civil. Em relação aos recursos naturais, cerca de um terço de seu consumo mundial é feito pela indústria da construção civil (THOMÉ, 2016). Estima-se, ainda, que cerca de 5\% das emissões de gás carbônico do efeito estufa estejam relacionados às indústrias cimenteiras, no processo de fabricação do cimento (EFEITO, 2020).

Sabe-se ainda que as atividades para obtenção de agregados utilizados na construção civil, como agregado miúdo, são realizadas através da exploração de jazidas, podendo ser jazidas de rio, de cava ou de dunas e praias (AGOPYAN e JOHN, 2011). A atividade de extração deste recurso natural é uma das que mais contribuem para a modificação da superfície da terra, resultando num impacto negativo sobre a água, o solo, o subsolo e a paisagem do rio de uma forma geral (NOGUEIRA, 2016). Para exploração de agregados graúdos, vale destacar também as atividades de mineração, através da exploração de jazidas e detonação de rochas em pedreiras.

Portanto, é relevante pensar em alternativas para a redução da utilização deste e de outros recursos naturais não renováveis, amenizando com isso essa problemática (CANELLAS, 2005). Atualmente vem sendo estudada a utilização de materiais reciclados na construção civil, visto que a reciclagem é de fundamental importância para que a sociedade possa construir um planeta mais saudável, com menos poluição e mais sustentabilidade.

Desta maneira, o presente trabalho teve como objetivo avaliar a resistência à compressão axial de um concreto classe C30 (resistência de $30 \mathrm{MPa}$ aos 28 dias de idade) dosado com um aditivo polifuncional FK830 e com agregados substituídos parcialmente por agregado de PET (politeraftalado de etileno).

Como objetivo secundário, o trabalho buscou avaliar, também, a consistência e a trabalhabilidade das dosagens.

Com base na literatura de referência, optou-se nessa pesquisa por dosar misturas com uso de aditivo polifuncional, uma vez que estes proporcionaram resultados satisfatórios de resistência em dosagens com agregados de PET, compensando, assim, possíveis perdas. $\mathrm{O}$ aditivo polifuncional escolhido foi o FK830, cedido por uma concreteira local que forneceu também seus traços de referência utilizados na região deste estudo. 
A Política Nacional de Resíduos Sólidos (PNRS), instituída pela lei federal $\mathrm{n}^{\mathrm{o}} 12305$ (BRASIL, 2010), prevê que sejam priorizadas atividades que não gerem resíduos, além da redução na geração, reutilização, reciclagem, tratamento e disposição final ambientalmente adequada dos resíduos sólidos urbanos.

Conforme visto em Agopyan e John (2011), devido ao aumento da população, houve um crescimento descontrolado na utilização e descarte de PET no Brasil nos últimos anos. A maioria dessas garrafas são descartadas em terrenos baldios, rios e oceanos, causando contaminação e contribuindo com o entupimento de bueiros e galerias, ocasionando enchentes. Nos dias atuais, reciclar tem sido considerado uma atitude de suma importância para redução dos impactos no meio ambiente.

Para Silva (2011), o aprimoramento dos métodos mencionados e o desenvolvimento de medidas mais racionais são capazes de contribuir com a redução de resíduos na construção civil, além de gerar uma nova possibilidade de utilizar diversos materiais de forma prática e sustentável.

Assim, desenvolver pesquisas voltadas para a redução da exploração de recursos naturais agregados naturais - e reciclagem de resíduos sólidos advindos de outras indústrias, como os resíduos de PET, é tarefa primordial para o desenvolvimento sustentável de um país.

\section{REFERENCIAL TEÓRICO}

\subsection{Materiais constituintes do concreto}

A NBR 8953 (ABNT, 2015) informa que concretos estruturais são aqueles de classe C20 (resistência a compressão axial mínima aos 28 dias de $20 \mathrm{MPa}$ ) ou superior. Concretos de resistência inferior a $20 \mathrm{MPa}$ não são estruturais e caso sejam utilizados devem ter seu desempenho atendido conforme a NBR 6118 - Projeto de estruturas de concreto (ABNT, 2014) e NBR 12655 Concreto de cimento Portland: Preparo, controle, recebimento e aceitação - procedimentos (ABNT, 2015). Seja com função estrutural ou não, os concretos são basicamente constituídos por aglomerante, água e agregados, podendo, ainda, conter aditivos, adições ou fibras em sua constituição. Esses materiais são descritos a seguir.

\subsubsection{Aglomerante}

$\mathrm{Na}$ construção civil, existem tipos de cimentos cujas funções variam de acordo com suas propriedades e aplicações. A classificação dos cimentos, quanto a seus constituintes, é apresentada a seguir, conforme a NBR 16697 (ABNT, 2018).

CPI - Cimento Portland comum;

CPI-S - Cimento Portland comum com adição;

CP II-E - Cimento Portland composto com escória;

CP II-Z - Cimento Portland composto com pozolana;

CP II-F - Cimento Portland composto com fíler;

CP III - Cimento Portland de alto-forno;

CP IV - Cimento Portland pozolânico;

CP V - ARI - cimento Portland de alta resistência inicial.

\subsubsection{Agregados}

Os agregados são materiais granulares, sem forma e volume definidos, de dimensões e propriedades adequadas às obras de engenharia, em especial aquelas que envolvam a fabricação de concretos e argamassas (BARBOSA, 2017). Os agregados devem ser compostos por grãos de 
minerais duros, compactos, duráveis, estáveis, serem limpos e não interferirem no endurecimento e nas reações de hidratação do cimento, além de não comprometerem a proteção contra corrosão da armadura (AGREGADOS, 2020). Barbosa (2017) afirma que esses materiais podem ter diferentes classificações. Segundo a sua origem, os agregados podem ser naturais, britados, artificiais ou reciclados. Os agregados naturais são aqueles derivados de rochas que existem na crosta terrestre e que, para sua utilização, só é preciso que passem por um processo de lavagem. É o caso da areia de rio, pedregulho, entre outros. Os agregados britados são aqueles derivados do processo de fragmentação de rocha. Existem ainda os agregados artificiais, produzidos por processos industriais, como a argila expandida e a vermiculita expandida. Existem ainda os agregados reciclados, que são materiais granulares obtidos a partir da reciclagem de rejeitos ou subprodutos da produção industrial, mineração ou construção e demolição da construção civil. É o caso da escória de alto forno que pode ser utilizada como agregado, dos resíduos de construção e demolição (RCD) e dos resíduos de PET, objeto de estudo desta pesquisa. Os agregados podem, ainda, ter uma classificação voltada para sua densidade, podendo ser: leves (como os agregados expandidos de argila), normais (como a brita) ou pesados (como a magnetita). Pode ser feita também a classificação dos agregados quanto à sua granulometria, conforme a NBR 7211 Agregados para concreto: especificação (Associação Brasileira de Normas Técnicas, 2019). Para isso, é importante conhecer o conjunto de peneiras sucessivas da NBR NM ISO 3310-1 (Associação Brasileira de Normas Técnicas, 2010). Suas aberturas estão especificadas em milímetros (mm):

- $\quad$ Série normal: $75 ; 37,5 ; 19 ; 9,5 ; 4,75 ; 2,36 ; 1,18 ; 0,6 ; 0,3 ; 0,15$

- Série intermediária: $63 ; 50 ; 31,5 ; 25 ; 12,5 ; 6,3$.

Segundo a NBR 7211 (Associação Brasileira de Normas Técnicas, 2019), define-se agregado miúdo como o agregado formado por grãos que passam pela peneira de $4,75 \mathrm{~mm}$. A NBR 9935 (Associação Brasileira de Normas Técnicas, 2011) destaca, ainda, que o agregado miúdo fica retido na peneira de $0,15 \mathrm{~mm}$. Já o agregado graúdo é o agregado com grãos que passam na peneira com abertura de malha $75 \mathrm{~mm}$ e ficam retidos na peneira de abertura $4,75 \mathrm{~mm}$. Ressalvas a essa regra são feitas nas tabelas 2 e 6 da referida norma, que estipula os limites inferiores e superiores da distribuição granulométrica desses agregados, em ensaio de granulometria realizado conforme a NBR NM 248 (Associação Brasileira de Normas Técnicas, 2003). Em relação à nomenclatura desses agregados quanto à granulometria, existem algumas variações comerciais em função da antiga classificação da NBR 7211 (Associação Brasileira de Normas Técnicas, 1983), que foi substituída pela versão 2009 e corrigida em 2019. A antiga versão da norma caracterizava os agregados miúdos como aqueles retidos na peneira de $0,075 \mathrm{~mm}$ e passantes na peneira de $4,8 \mathrm{~mm}$. Já os agregados graúdos eram classificados como aqueles retidos na peneira de 4,8 mm e passantes na peneira de $152 \mathrm{~mm}$. Os agregados miúdos eram subdivididos em quatro zonas: zona 1 (muito fina); zona 2 (fina); zona 3 (média); zona 4 (grossa). No que se refere aos agregados graúdos, sua classificação granulométrica envolvia diferentes graduações: brita 0, 1, 2, 3, 4 e 5. Nesse sentido, em sua nova versão, a NBR 7211 (Associação Brasileira de Normas Técnicas, 2019) também estipula faixas de variação dos agregados graúdos, conforme Tabela 6 desta norma.

- Primeira zona granulométrica: 4,75 $\mathrm{mm}$ a 12,5 $\mathrm{mm}$ - chamado também de pedrisco (Associação Brasileira de Normas Técnicas, 2011);

- Segunda zona granulométrica: 9,5 $\mathrm{mm}$ a $25 \mathrm{~mm}$;

- Terceira zona granulométrica: 19 a $31,5 \mathrm{~mm}$;

- Quarta zona granulométrica: 25 a $50 \mathrm{~mm}$;

- Quinta zona granulométrica: 37,5 a $75 \mathrm{~mm}$. 
Além das classificações acima, a NBR 9935 (Associação Brasileira de Normas Técnicas, 2011) define, ainda, pó de pedra como o material granular resultante da britagem de rocha que passa na peneira de malha $6,3 \mathrm{~mm}$. O pó de pedra é um resíduo proveniente do processo da extração de brita, ficando acumulado em abundância nos pátios das pedreiras.

\section{- Adições e aditivos}

Nas matrizes cimentícias, aditivos e adições vêm sendo empregados nos últimos anos, a fim de modificar uma ou mais de suas propriedades. Na linguagem técnica, os termos são, ainda, confundidos. Pode-se dizer que adições podem ser consideradas como qualquer material de origem mineral, capaz de somar ou substituir o cimento em matrizes cimentícias, alterando suas características químicas ou físicas. É o caso do metacaulim, da sílica ativa, cinza volante, entre outros (MEHTA e MONTEIRO, 1994).

A utilização de certos tipos de adições, assim como de agregados reciclados, reforça o pensamento de sustentabilidade, uma vez que busca o desenvolvimento tecnológico do concreto a partir de resíduos. É o caso das escórias de alto forno e cinzas volantes, que passam a ter outras aplicações além do descarte no meio ambiente.

Os aditivos por sua vez são materiais de origem química adicionados em pequenas quantidades nas matrizes cimentícias, sendo possível a alteração das propriedades de concretos e argamassas no estado fresco e no estado endurecido. $\mathrm{O}$ uso de aditivos interfere diretamente na perda ou ganho de resistência mecânica em um concreto, além de afetar sua consistência e trabalhabilidade, sua permeabilidade, dentre outras propriedades do concreto.

Os principais aditivos disponíveis no mercado são os redutores de água ou plastificantes, os superplastificantes, os hiperplastificantes, os aceleradores ou retardadores de pega, incorporadores de ar, polifuncionais/multifuncionais, entre outros, como visto na NBR 11768 (Associação Brasileira de Normas Técnicas, 2011).

A NBR 11768 (Associação Brasileira de Normas Técnicas, 2011) classifica os aditivos polifuncionais como aqueles aditivos plastificantes que permitem maior dosagem que os plastificantes convencionais. Assim, os polifuncionais conferem maior trabalhabilidade e/ou redução de água. Já os superplastificantes tem maior efeito de redução de água e/ou ganho de trabalhabilidade que os plastificantes de modo geral. São, assim, considerados de alta eficiência.

Os aditivos incorporadores de ar permitem que o concreto fique resistente a baixas temperaturas e a ataques químicos provocados por sais de degelo. Já os modificadores de pega são aqueles utilizados para acelerar ou retardar as reações de hidratação do cimento.

\section{- Fibras}

Mehta e Monteiro (1994) destacam que outro material muito empregado nas matrizes cimentícias são as fibras. Elas podem ser de diversos tipos, como: fibras de aço, de polipropileno (microfibras de monofilamentos ou fibriladas, e macro fibras poliméricas), fibras de vidro, de carbono, de náilon, madeira, sisal, entre outras. As fibras atuam como ponte de transferência de tensão nas fissuras, e podem: aumentar a resistência à tração e a ductilidade dos concretos, melhorar o comportamento no estado fresco e no processo de endurecimento. Podem ser utilizadas para o controle de fissuração plástica em pavimentos, para reduzir ou interromper o processo de fissuras, para reforço do concreto endurecido, entre outras funções.

\section{MATERIAIS E MÉTODOS}


Esta pesquisa contou com o desenvolvimento de ensaios de resistência à compressão axial e de consistência, para avaliação da resistência mecânica e trabalhabilidade das misturas de concreto dosadas com agregado de PET em substituição aos agregados miúdo e graúdo.

Assim, primeiramente, buscou-se destacar os materiais empregados e, posteriormente, o programa experimental.

\subsection{Materiais empregados}

Para dosagem das misturas e moldagem dos corpos de prova, foram empregados nas matrizes cimentícias os seguintes materiais:

- Aglomerante - cimento Portland CPII - E, classe $32 \mathrm{MPa}$;

- Agregado miúdo - areia natural do Rio Pomba, de Cataguases, Minas Gerais;

- Pó de pedra - agregado britado de origem gnáissica, obtido de uma pedreira em Cataguases, Minas Gerais;

- Pedrisco - agregado graúdo britado da primeira zona granulométrica 4,75/12,5 obtido de uma pedreira em Cataguases, Minas Gerais;

- Brita 9,5/25 - agregado graúdo britado da segunda zona granulométrica 9,5/25 obtida de uma pedreira em Cataguases, Minas Gerais.

- Aditivo polifuncional FK-830;

- Agregado reciclado de PET, para substituição dos demais agregados em diferentes proporções.

A Figura 01 ilustra o agregado de PET utilizado nesta pesquisa. Ele foi obtido a partir de garrafa PET triturada em triturador mecânico na cidade de Cataguases (MG). Destaca-se que foram identificadas limitações do equipamento em relação à granulometria do produto final. Não foi possível obter um produto que atenda à uma ampla faixa granulométrica. Assim, ao ser passado no jogo de peneiras, identificou-se que o material é $100 \%$ passante na peneira de $4,75 \mathrm{~mm}$ e $100 \%$ retido na peneira de $2,36 \mathrm{~mm}$. 


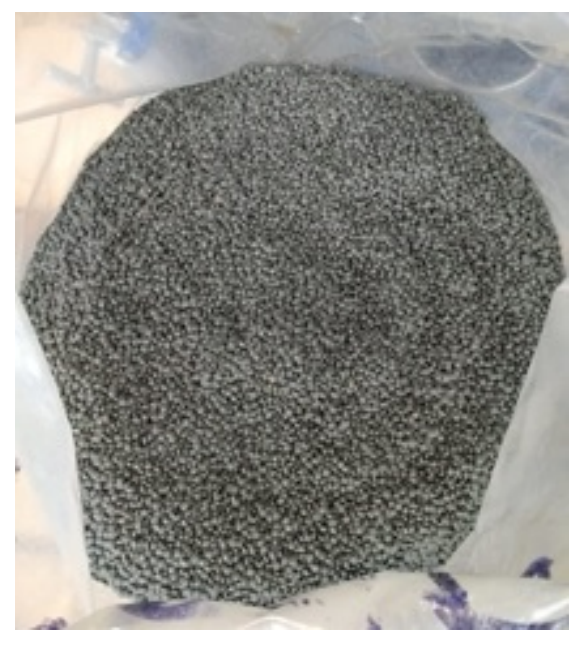

Figura 01. Agregado reciclado de PET.

\subsection{Traços empregados nas dosagens}

O traço de referência dessa mistura (CA) foi obtido de uma concreteira na cidade de Cataguases (MG) para dosagem de um concreto C30 (resistência de $30 \mathrm{MPa}$ aos 28 dias de idade). Os materiais empregados na dosagem foram os mesmos empregados nesta pesquisa. O Quadro 1 indica as dosagens para o traço de referência, considerando uma betonada em betoneira estacionária de 150 litros.

Quadro 1. Traço de referência - CA.

\begin{tabular}{|c|c|}
\hline \multicolumn{2}{|c|}{ Concreto de referência - CA } \\
\hline Material & Massa (g) \\
\hline Aglomerante & 5.365 \\
\hline Agregado miúdo & 11.290 \\
\hline Pó de pedra & 1.220 \\
\hline Pedrisco & 6.025 \\
\hline Brita 9,5/25 & 8.995 \\
\hline Aditivo FK830 & 25.40 \\
\hline Água & 2.490 \\
\hline
\end{tabular}

Fonte: adaptado de uma concreteira na cidade de Cataguases (2020)

Para as substituições dos agregados por agregado reciclado de PET, foi verificado um problema em relação às dimensões dos materiais, uma vez que o agregado de PET não possui as mesmas faixas granulométricas da areia e pó de pedra utilizados nesta pesquisa. Constatou-se que, embora possa ser classificado como agregado miúdo (100\% do material é passante na peneira de 4,75 mm), o agregado de PET tem granulometria muito uniforme, se comparado à areia e ao pó de pedra, além de possuir maiores dimensões. Assim, baseando-se na pesquisa de Modro e Oliveira (2009), optou-se por substituir de forma conjunta os agregados. Ou seja, o agregado de PET foi utilizado para substituir uma mistura de agregado miúdo, pó de pedra e pedrisco (da zona granulométrica 4,75/12,5). A brita da zona granulométrica 9,5/25 não foi substituída, por distanciar-se muito da granulometria do agregado reciclado de PET. 
A partir do traço de referência, foram retiradas massas de agregados correspondentes a 5\%, $10 \%, 20 \%$ e $50 \%$ das massas iniciais (do traço de referência) de cada um desses agregados. No momento de substituir os agregados pelo agregado reciclado de PET, optou-se por fazer as substituições em volume, uma vez que o agregado de PET tem densidade muito diferente dos agregados utilizados nesta pesquisa, o que inviabilizaria as substituições em massa. Essa consideração também foi feita nos trabalhos de Modro e Oliveira (2009), Jardim (2016) e Gorges et al. (2019). Assim, nos traços com uso do agregado de PET em substituição aos agregados miúdo, pó de pedra e pedrisco, foram empregadas as seguintes massas de materiais nas betonadas, conforme Quadro 2. As siglas utilizadas para descrever as dosagens são:

- $\quad$ CA - concreto aditivado de referência, sem PET;

- CAPET5 - concreto aditivado com 5\% de substituição de agregados por agregado de PET;

- CAPET10 - concreto aditivado com 10\% de substituição de agregados por agregado de PET;

- CAPET20 - concreto aditivado com $20 \%$ de substituição de agregados por agregado de PET;

- CAPET50 - concreto aditivado com 50\% de substituição de agregados por agregado de PET.

Quadro 2. Traços com substituição.

\begin{tabular}{|c|c|c|c|}
\hline \multicolumn{2}{|c|}{$\begin{array}{c}\text { Concreto com substituição de 5\% - } \\
\text { CAPET5 }\end{array}$} & \multicolumn{2}{|c|}{$\begin{array}{c}\text { Concreto com substituição de } 10 \% \text { - } \\
\text { CAPET10 }\end{array}$} \\
\hline Material & Massa (g) & Material & Massa (g) \\
\hline Aglomerante & 5.365 & Aglomerante & 5.365 \\
\hline Agregado miúdo & 10.726 & Agregado miúdo & 10.161 \\
\hline Pó de pedra & 1.159 & Pó de pedra & 1.098 \\
\hline Pedrisco & 5.724 & Pedrisco & 5.423 \\
\hline Brita 9,5/25 & 8.995 & Brita $9,5 / 25$ & 8.995 \\
\hline Aditivo FK830 & 25.40 & Aditivo FK830 & 25.40 \\
\hline Água & 2.490 & Água & 2.490 \\
\hline \multicolumn{2}{|c|}{$\begin{array}{l}\text { Agregado de PET: } 5 \% \text { do volume do } \\
\text { material retirado }\end{array}$} & \multicolumn{2}{|c|}{$\begin{array}{c}\text { Agregado de PET: } 10 \% \text { do volume do } \\
\text { material retirado }\end{array}$} \\
\hline \multicolumn{2}{|c|}{$\begin{array}{c}\text { Concreto com substituição de } 20 \% \text { - } \\
\text { CAPET20 }\end{array}$} & \multicolumn{2}{|c|}{$\begin{array}{c}\text { Concreto com substituição de 50\% - } \\
\text { CAPET50 }\end{array}$} \\
\hline Material & Massa (g) & Material & Massa (g) \\
\hline Aglomerante & 5.365 & Aglomerante & 5.365 \\
\hline Agregado miúdo & 9.032 & Agregado miúdo & 5.645 \\
\hline Pó de pedra & 976 & Pó de pedra & 610 \\
\hline Pedrisco & 4.820 & Pedrisco & 3.013 \\
\hline Brita $9,5 / 25$ & 8.995 & Brita $9,5 / 25$ & 8.995 \\
\hline Aditivo FK830 & 25.40 & Aditivo FK830 & 25.40 \\
\hline Água & 2.490 & Água & 2.490 \\
\hline \multicolumn{2}{|c|}{$\begin{array}{l}\text { Agregado de PET: } 20 \% \text { do volume do } \\
\text { material retirado }\end{array}$} & \multicolumn{2}{|c|}{$\begin{array}{c}\text { Agregado de PET: } 50 \% \text { do volume do } \\
\text { material retirado }\end{array}$} \\
\hline
\end{tabular}

Fonte: Os autores (2020) 


\subsection{Preparo, moldagem dos corpos de prova, cura e ensaios realizados}

\section{- Preparo}

Para cada traço dos Quadros 1 e 2, foram moldados 5 corpos de prova no dia 17/10/2020. A mistura dos materiais em betoneira estacionária foi feita segundo as recomendações da NBR 12655 (Associação Brasileira de Normas Técnicas, 2015).

A norma recomenda que para betoneiras estacionárias o procedimento de preparo da mistura siga as recomendações do fabricante. Assim, inicialmente buscou-se pesar todos os materiais e verificar o volume de agregado de PET empregado em cada mistura. Tendo pesado os materiais em balança de precisão de $0,1 \mathrm{~g}$, foi feita a mistura do aditivo na água de amassamento. Posteriormente, ligou-se a betoneira estacionária, previamente umedecida, e foi realizada a mistura dos materiais aos poucos e na seguinte ordem: britas, 1/3 do volume da mistura de água e aditivo, cimento, $1 / 3$ do volume da mistura de água e aditivo, areia pó de pedra e pet, restante da água. $\mathrm{O}$ procedimento de mistura foi feito até o material ficar homogêneo e sem ultrapassar 5 minutos.

\section{- Moldagem dos corpos de prova}

Antes de realizar a moldagem dos corpos de prova, foi feita a verificação do abatimento do tronco de cone (slump test) para avaliação da consistência dos concretos, conforme previsto na NBR NM 67 (Associação Brasileira de Normas Técnicas, 1998). A Figura 02 ilustra o ensaio de abatimento do tronco de cone. As recomendações normativas foram observadas, de modo que o ensaio foi realizado com preenchimento do molde em três camadas, havendo compactação de cada camada com 25 golpes.

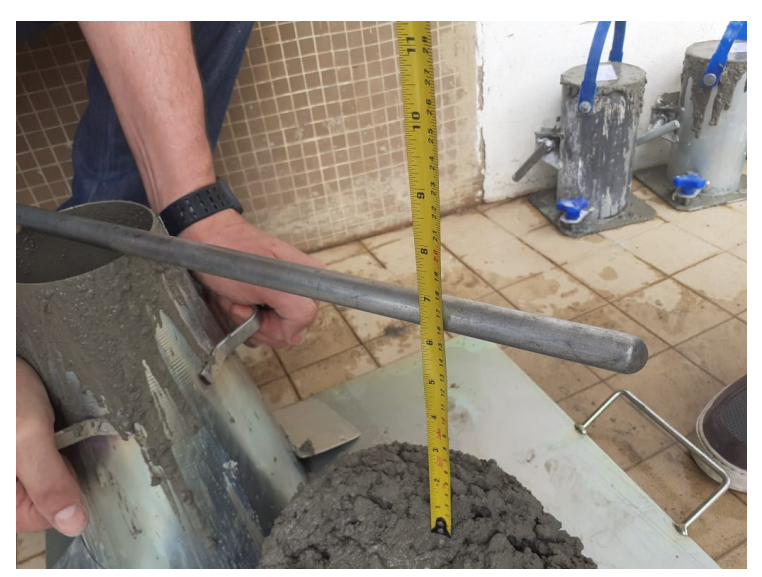

Figura 02. Verificação do abatimento do tronco de cone.

A NBR 5738 (Associação Brasileira de Normas Técnicas, 2015) especifica o procedimento de moldagem dos corpos de prova de concreto. Os corpos de prova de concreto utilizados são cilíndricos de dimensões $10 \mathrm{~cm}$ x $20 \mathrm{~cm}$. Vale destacar algumas recomendações normativas, como a dimensão da base do corpo de prova deve ser no mínimo três vezes superior à dimensão máxima do agregado utilizado. Os moldes devem ser revestidos por lubrificante ou óleo em sua face interna. Nos corpos de prova cilíndricos foi feito adensamento manual em duas camadas, conferidos 12 golpes por camada. Observou-se, ainda, a recomendação normativa de rasamento do topo dos corpos de prova com a colher de pedreiro. 
Após a moldagem, os corpos de prova foram identificados e armazenados em local protegido de intempéries, para evitar a perda de água do material. Eles ficaram $24 \mathrm{~h}$ no processo de cura inicial. Findado o período de cura inicial, os corpos de prova foram desmoldados e novamente identificados. Foram, então, submersos em tanque de imersão de solução saturada de hidróxido de cálcio até atingirem 28 dias de idade. Buscou-se manter a temperatura em $23+/-2^{\circ} \mathrm{C}$.

\section{- Ensaio de resistência à compressão axial - execução, resultados e interpretação dos dados}

Terminado o período de cura dos corpos de prova, eles puderam ser retirados do tanque e ensaiados. Para realização do ensaio de resistência a compressão axial, é necessário que seja feita preparação das bases com retificação ou capeamento com material de até $3 \mathrm{~mm}$ de espessura em cada base (Associação Brasileira de Normas Técnicas, 2015). Por falta de equipamento para retificação, esta etapa não foi realizada na pesquisa para nenhum corpo de prova.

Os ensaios de resistência a compressão axial foram feitos no dia 14/11/2020 com ruptura em prensa manual. Foram atendidos os critérios da NBR 5739 - Concreto - ensaio de compressão de corpos de prova cilíndricos (Associação Brasileira de Normas Técnicas, 2015).

Para avaliação estatística do desempenho e confiabilidade dos resultados dos ensaios, foi utilizado o anexo B da NBR 5739 (Associação Brasileira de Normas Técnicas, 2016). Para esta avaliação, é recomendado que a amostra (ou seja, cada dosagem) tenha dez ou mais exemplares e que cada exemplar tenha no mínimo 2 corpos de prova. Para cada exemplar, calcula-se a amplitude dos resultados (Ai), considerando o número de exemplares n e o número de corpos de prova por exemplar. Assim, o desvio padrão é calculado para a amostra, conforme anexo B da NBR 5739 (Associação Brasileira de Normas Técnicas, 2016).

Neste trabalho, para cada amostra (cada traço ensaiado), foi desenvolvido apenas um exemplar, com 5 corpos de prova cada um. Deste modo, para cada traço o desvio padrão foi dado pela equação 1, considerando A a amplitude dos resultados e 2,326 o coeficiente de ponderação utilizado quando são moldados 5 corpos de prova por exemplar.

$$
\mathrm{Se}=\mathrm{A} / 2,326
$$

Assim, o coeficiente de variação dentro do ensaio (Cve) pode ser calculado a partir de Se e da resistência média ( $\mathrm{fcm}$ ) obtida nos exemplares. Como nesta pesquisa foi desenvolvido apenas um exemplar por amostra, fcm foi dada a partir das médias dos resultados dos corpos de prova.

Deste modo, a equação 2 expressa o coeficiente de variação dentro do ensaio (Cve):

$$
\mathrm{Cve}=[\mathrm{Se} / \mathrm{fcm}] \times 100
$$

A avaliação estatística quanto à dispersão dos resultados é dada atribuindo-se diferentes níveis, como descrito a seguir:

- $\quad$ Nível 1: Excelente (Cve $\leq 3,0)$;

- Nível 2: Muito bom $(3 \leq \mathrm{Cve} \leq 4,0)$;

- Nível 3: $\operatorname{Bom}(4,0 \leq \mathrm{Cve} \leq 5,0)$;

- Nível 4: Razoável $(5,0 \leq \mathrm{Cve} \leq 6,0)$;

- Nível 5: Deficiente (Cve $\geq 6,0)$.

\section{RESULTADOS E DISCUSSÕES}


De um modo geral, pode-se indicar no Quadro 04 os resultados obtidos de abatimento e as médias de resistência à compressão axial obtidas para cada dosagem.

Quadro 04. Resultados encontrados.

\begin{tabular}{|c|c|c|}
\hline Identificação & $\begin{array}{c}\text { Slump Test } \\
\text { (mm) }\end{array}$ & $\begin{array}{c}\text { Média de resistência } \\
\text { a compressão axial } \\
\text { (MPa) }\end{array}$ \\
\hline CA & 152 & 16,59 \\
\hline CAPET5 & 158 & 16,92 \\
\hline CAPET10 & 80 & 13,10 \\
\hline CAPET20 & 140 & 10,99 \\
\hline CAPET50 & 34 & 6,17 \\
\hline
\end{tabular}

Fonte: Os autores (2020)

Para o concreto de referência, foi possível identificar os resultados encontrados de resistência mecânica no gráfico da Figura 03. Os resultados variaram entre 13,19 $\mathrm{MPa}$ e 18,24 $\mathrm{MPa}$, com uma amplitude de 5,05 Mpa, desvio padrão (Se) de 2,17 MPa, resistência média (fcm) de 16,59 MPa e coeficiente de variação dentro do ensaio (Cve) de 13\% (indicando deficiência no procedimento de ensaio).

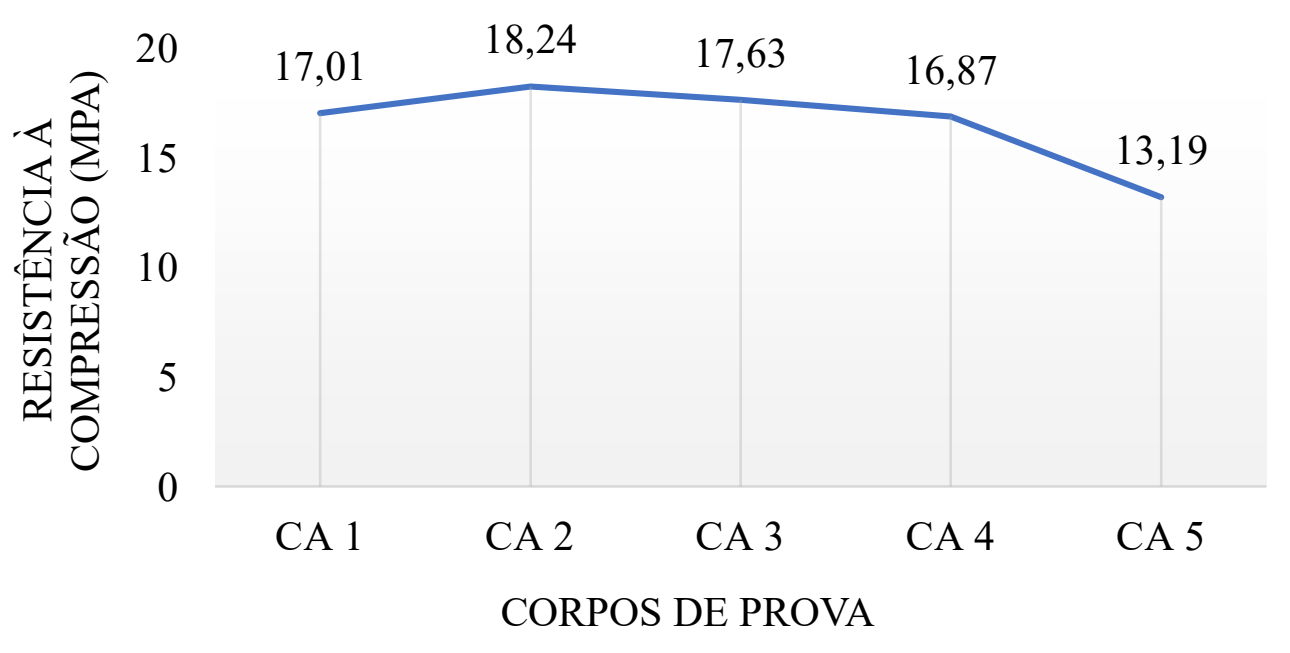

Figura 03. Resultados encontrados de resistência mecânica para o traço de referência - CA.

Para os traços com substituição dos agregados por agregado reciclado de PET, foi feito o mesmo procedimento de análise de dados. Para a dosagem com substituição de $5 \%$, observou-se um coeficiente de variação dentro do ensaio (Cve) de 4,1\% (considerado bom). Nas dosagens com $10 \%$ de substituição, verificou-se um Cve de 12\%, também deficiente. Para as substituições de $20 \%$, o Cve obtido foi de $10 \%$ (deficiente) e para as dosagens com $50 \%$ de substituição, o Cve foi também de $4,1 \%$, considerado bom.

Vale destacar que esses resultados não retratam o desempenho do agregado de PET na mistura como bom ou deficiente, mas a confiabilidade dos resultados encontrados. 
Analisando os resultados obtidos, percebe-se pelo Quadro 04 que os concretos com agregado de PET tendem a perder consistência e trabalhabilidade. Esse resultado está de acordo com os resultados da literatura e pode consultado na pesquisa de Modro e Oliveira (2009). Assim, para que se tenha um bom desempenho dessas misturas, é indicado o uso de aditivos polifuncionais, plastificantes ou superplastificantes, que possam contribuir na melhoria desta propriedade, como foi feito neste trabalho. Observa-se ainda que o CAPET10 teve um valor de consistência bastante divergente dos demais. Acredita-se que isso aconteceu devido a erro de execução do ensaio no momento de retirada do molde do slump test, de modo que a avaliação do abatimento do tronco de cone ficou comprometida (Figura 04).

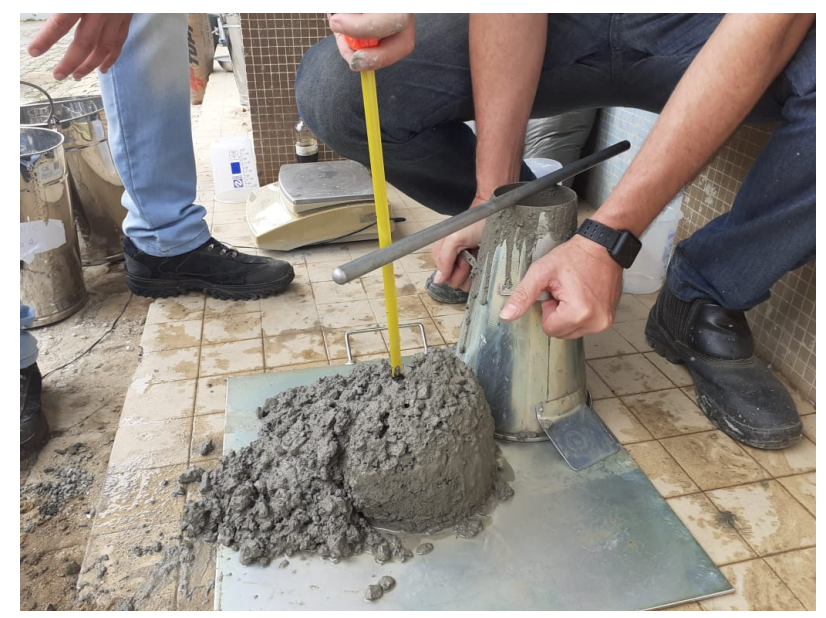

Figura 04: Erros de execução do ensaio no CAPET10

Em relação aos resultados obtidos de resistência à compressão axial, algumas considerações podem ser feitas:

a) Todas as dosagens tiveram resultados inferiores ao resultado esperado de dosagem do traço (de $30 \mathrm{MPa}$ ). Acredita-se que a justificativa para esse fato esteja vinculada à erros de moldagem dos corpos de prova, uma vez que a moldagem foi realizada sem o controle tecnológico de concreteira. Outros fatores que justificam os resultados são a falta de retificação dos topos e das bases dos corpos de prova, por falta de equipamento, além do uso de prensa manual aliada à pouca experiencia dos operadores.

b) Existe, através do Quadro 04, um indicativo de padrão de comportamento da resistência do concreto dosado com agregado reciclado de PET: observa-se que a resistência à compressão do concreto diminui quando o percentual de substituição aumenta.

O resultado está de acordo com os resultados encontrados por Modro e Oliveira (2009), Canellas (2005) e Almeida et al. (2004). Modro e Oliveira (2009) explicam que o material de PET tem menor interação química com a matriz cimentícia e é um material com maior porosidade residual. Vale destacar também a menor resistência mecânica do agregado de PET em relação aos agregados minerais, que são muito mais resistentes mecanicamente.

c) Em relação à confiabilidade dos resultados e coeficiente de variações obtidos, observa-se que os resultados obtidos para o concreto de referência e os concretos com substituição de 10 e $20 \%$ tiveram grande dispersão de resultados e podem ser considerados deficientes para uma análise mais criteriosa. Os resultados obtidos para as substituições de 5\% e 50\% tiveram uma boa confiabilidade e a partir deles algumas conclusões podem ser tiradas, como a possibilidade de equiparação de propriedades de um concreto com 5\% de substituição dos agregados por agregado de PET em relação ao de referência. Outra conclusão à qual se chega é que as dosagens com $50 \%$ de 
substituição são inviáveis tecnicamente, uma vez que atingiram níveis de resistência bastante baixos, frente às demais.

d) Por não terem atingido a resistência mínima de $20 \mathrm{MPa}$ para concretos estruturais (ABNT NBR $6118,2014)$, os materiais desenvolvidos nesta pesquisa, a princípio, não são indicados para uso como concreto estrutural. Sugere-se confirmação dos resultados em pesquisas futuras. Gorges et al. (2019) também encontraram um comportamento semelhante entre concretos de referência (sem substituição) e concretos dosados com substituição de até $10 \%$ de seus agregados por agregados de PET. Modro e Oliveira (2009) encontraram em sua pesquisa viabilidade técnica para uso não estrutural das dosagens obtidas com substituição de agregados por PET. Entre esses usos, os autores destacam: alvenaria de fechamento interna, capas de lajes pré-moldadas ou nervuradas, material de enchimento, entre outros.

\section{CONSIDERAÇÕES FINAIS}

Observou-se nesta pesquisa a viabilidade de substituição dos agregados naturais por agregados reciclados de PET para produção de concretos sem fins estruturais. Se corrigidas as variações e irregularidades apontadas nesta pesquisa em estudos futuros, acredita-se ser possível obter concretos com substituição dos agregados por agregado reciclado de PET com resistências superiores a $20 \mathrm{MPa}$, especialmente na dosagem do CAPET5, com substituição de 5\%, que foi a dosagem que obteve melhor resultado e teve comportamento semelhante ao concreto de referência.

Pode-se dizer que foi possível observar um padrão de comportamento compatível com os resultados encontrados na literatura: quanto maior o teor de substituições, menor a resistência à compressão das misturas e menor sua trabalhabilidade. Assim, o uso de aditivos que garantam ganhos de trabalhabilidade é altamente recomendado, como foi feito nesta pesquisa (com emprego de aditivo polifuncional FK830).

Acredita-se que garantir as propriedades técnicas de concretos sustentáveis é tarefa primordial para o desenvolvimento sustentável de um país e garantia da qualidade e desempenho das edificações, além de prevenir a ocorrência de manifestações patológicas futuras.

Para trabalhos futuros, recomenda-se a realização de mais exemplares por amostra, para maior base de dados estatísticos. Recomenda-se também a retificação dos corpos de prova e uso de prensa hidráulica para rompimento dos corpos de prova. Outra possibilidade a ser avaliada em pesquisas futuras é a trituração do agregado de PET em outro equipamento, até ser obtida a granulometria ótima dos agregados miúdos, de modo que areias e agregado de PET tenham a mesma distribuição granulométrica e o agregado de PET possa ser utilizado para substituir somente a areia ou a areia e o pó de pedra.

\section{AGRADECIMENTOS}

Agradecimentos às Faculdades Unificadas de Cataguases, por ceder espaço e equipamentos para realização desta pesquisa.

\section{REFERÊNCIAS}

AGOPYAN, V.; JOHN, V. M. O desafio da sustentabilidade na construção. São Paulo: Blucher, 2011.

AGREGADOS para concreto: o que são e para que servem? Tecnosil Br, 2020. Disponível em: $<$ https://www.tecnosilbr.com.br/agregados-para-concreto-o-que-sao-e-para-que-servem/> Acesso em: 30 de novembro de 2020. 
ALMEIDA, M.; JUNIOR, M.; SONCIM, S.; JUNIOR, G. Uso de areia de PET na fabricação de concretos. In: Congresso Brasileiro de Ciência e Tecnologia e Resíduos e Desenvolvimento Sustentável. Livro de Resumos, pp. 39, Santa Catarina, Outubro, 2004.

ASSOCIAÇÃO BRASILEIRA DE NORMAS TÉCNICAS. NBR 5738 - Concreto Procedimento para moldagem e cura dos corpos de prova. Rio de Janeiro, 2015.

ASSOCIAÇÃO BRASILEIRA DE NORMAS TÉCNICAS. NBR 5739 - Ensaio de compressão de corpressão de corpos de prova cilíndricos. Rio de Janeiro, 2018.

ASSOCIAÇÃO BRASILEIRA DE NORMAS TÉCNICAS. NBR 6502 - Rochas e solos. Rio de Janeiro, 1995.

ASSOCIAÇÃO BRASILEIRA DE NORMAS TÉCNICAS. NBR 6118 - Projeto de estruturas de concreto - procedimento. Rio de Janeiro, 2014.

ASSOCIAÇÃO BRASILEIRA DE NORMAS TÉCNICAS. NBR 7211 - Agregados para concreto - especificação. Rio de Janeiro, 2019.

ASSOCIAÇÃO BRASILEIRA DE NORMAS TÉCNICAS. NBR 8953 - Concreto para fins estruturais - Classificação pela massa específica, por grupos de resistência e consistência. Rio de Janeiro, 2015.

ASSOCIAÇÃO BRASILEIRA DE NORMAS TÉCNICAS. NBR 9935 - Agregados terminologia. Rio de Janeiro, 2011.

ASSOCIAÇÃO BRASILEIRA DE NORMAS TÉCNICAS. NBR 11768 - Aditivos para concreto de cimento Portland. Rio de Janeiro, 2011.

ASSOCIAÇÃO BRASILEIRA DE NORMAS TÉCNICAS. NBR 12655 - Concreto de cimento Portland - preoaro, controle, recebimento e aceitação - procedimento. Rio de Janeiro, 2015.

ASSOCIAÇÃO BRASILEIRA DE NORMAS TÉCNICAS. NBR 16697 - Cimento Portland Requisitos. Rio de Janeiro, 2018.

ASSOCIAÇÃO BRASILEIRA DE NORMAS TÉCNICAS. NBR NM 52 - Agregado miúdo: determinação das massas específicas e massas específicas aparentes. Rio de Janeiro, 2009.

ASSOCIAÇÃO BRASILEIRA DE NORMAS TÉCNICAS. NBR NM 53 - Agregado miúdo: determinação das massas específicas e massas específicas aparentes. Rio de Janeiro, 2003.

ASSOCIAÇÃO BRASILEIRA DE NORMAS TÉCNICAS. NBR NM 67 - Concreto determinação da consistência pelo abatimento do tronco de cone. Rio de Janeiro, 1998.

ASSOCIAÇÃO BRASILEIRA DE NORMAS TÉCNICAS. NBR NM 248 - Determinação da composição granulométrica. Rio de Janeiro, 2003. 
ASSOCIAÇÃO BRASILEIRA DE NORMAS TÉCNICAS. NBR NM ISO 3310-1 - Peneiras de ensaios - requisitos técnicos e verificação - Parte 1. Rio de Janeiro, 2010.

BARBOSA, M. Materiais de Construção Civil. Juiz de Fora, 2017 (Apostila).

CANELLAS, S.S. Reciclagem de PET, visando a substituição de agregado miúdo em argamassas, Dissertação M.Sc., PUC, Rio de Janeiro, RJ, Brasil, 2005.

EFEITO estufa e aquecimento global. Ministério Do Meio Ambiente, 2020. Disponível em: $<$ https://www.mma.gov.br/informma/item/195-efeito-estufa-e-aquecimento-global $>$. Acesso em 21 de Março de 2020.

GORGES, G.; PERES, G.; GABRIEL, P. CASOLA, M.; CÂMARA, E. Substituição parcial do agregado miúdo natural por cerâmica vermelha e polietileno tereftalado (PET) em concreto. In: Anais do Concresso Técnico e Científico da Engenharia e da Agronomia; 17 - 19 set 2019; Palmas, TO, Brasil; 2019. p. 1-5.

JARDIM, R. R. Estudo da viabilidade da substituição parcial do agregado miúdo por agregado miúdo reciclado de PET em concretos convencionais. Trabalho de Conclusão de Curso, Universidade Federal do Pampa, Alegrete, RS, Brasil, 2016.

MEHTA, P. K.; MONTEIRO, P. J. M. Concreto: estrutura, propriedades e materiais. São Paulo: PINI, 573 p., 1994.

MODRO, N.; OLIVEIRA, A. Avaliação de concreto de cimento Portland contendo resíduos de PET. Revista Matéria, v. 14, n.1, pp. 725-736, 2009.

THOMÉ, Brenda Bressan. Desperdício na construção civil: impactos no meio ambiente. Sienge Plataforma, 2016. Disponível em: < https://www.sienge.com.br/blog/desperdicio-na-construcaocivil-impactos-no-meio-ambiente/> Acesso em: 30 de novembro de 2020. 